\title{
Expressive and Receptive Language Characteristics in Three-Year-Old Preterm Children with Extremely Low Birth Weight
}

\author{
Kristiane M. Van Lierde ${ }^{a}$ Herbert Roeyers $^{b} \quad$ Sabine Boerjan $^{a} \quad$ Isabel De Groote ${ }^{b, c}$ \\ a Department of Otorhinolaryngology, Head and Neck Surgery and Speech and Language Pathology, \\ Ghent University Hospital, and ${ }^{\mathrm{b}}$ Department of Experimental-Clinical and Health Psychology, Ghent University, \\ Ghent, and ' ${ }^{C}$ nniversity Centre of Child and Adolescent Psychiatry, Antwerp, Belgium
}

\section{Key Words}

Preterm children $\cdot$ Expressive language $\cdot$ Receptive

language $\cdot$ Extremely low birth weight
These communication disorders appear unrelated to neurological or sensorial impairments, but can be partly explained by a decreased general mental functioning.

Copyright $\odot 2009$ S. Karger AG, Basel

\section{Introduction}

Several studies during the 1980s suggested a high incidence of expressive and receptive language problems, accompanied by more general developmental problems, among very low birth weight children (defined as $<1,500 \mathrm{~g}$ ), as reviewed by Aram et al. [1].

An in depth analysis of the language development in 3 -year-old extremely low birth weight (ELBW; defined as $<1,000 \mathrm{~g}$ ) preterm children has - to the best of our knowledge - not frequently been reported yet. Only the investigation of Grunau et al. [2] compared language outcome at 3 years in a group of 23 ELBW preterm children with a matched sample of 23 full-term children with normal birth weight (FBW). The children below 1,000 g who showed normal overall intellectual scores (Stanford-Binet Intelligence Scale) appeared to function linguistically less well than full-term peers. The group with ELBW used less complex expressive language (spontaneous language samples) and showed lower receptive understanding (Peabody Picture Vocabulary Test), auditory memory

\section{KARGER \\ Fax +4161306 1234 \\ E-Mail karger@karger.ch}

www.karger.com
(C) 2009 S. Karger AG, Basel

1021-7762/09/0615-0296\$26.00/0

Accessible online at:

www.karger.com/fpl
Prof. Kristiane Van Lierde

University Hospital Gent, 2P1

De Pintelaan 185

BE-9000 Gent (Belgium)

Tel. +32 9332 2391, E-Mail kristiane.vanlierde@ugent.be 
Table 1. Characteristics of the ELBW and FBW children

\begin{tabular}{lccccc}
\hline \multirow{2}{*}{ Characteristics } & \multicolumn{2}{l}{ ELBW $(\mathrm{n}=15)$} & & \multicolumn{2}{l}{ FBW $(\mathrm{n}=19)$} \\
\cline { 2 - 3 } \cline { 5 - 6 } & mean $\pm \mathrm{SD}$ & range & & mean \pm SD & range \\
\hline Birth weight, g & $792.9 \pm 95.8$ & $605-1,000$ & & $3,500 \pm 424.5$ & $2,800-4,260$ \\
Gestational age, weeks & $25.1 \pm 0.8$ & $23-26$ & & $39.9 \pm 0.8$ & $39-41$ \\
Chronological age, months & $43.1 \pm 3.54$ & $38-49$ & & $38.45 \pm 4.41$ & $31-44$ \\
Corrected age, months & $39.4 \pm 3.5$ & $35-45$ & & \\
\hline
\end{tabular}

and verbal reasoning in comparison with the matched control group. Also in other studies $[3,4]$ preterm children with a birth weight of $<1,000 \mathrm{~g}$ were present, but the results of the language assessments of the children at the age of 2, 3.5 and 5 years were mentioned together with the data of the preterm children with a very low birth weight and low birth weight. A delineation of the specific expressive and receptive language characteristics in the preterm children with ELBW from these studies is therefore somewhat difficult.

The main purpose of this study was to assess and analyze the expressive and receptive language characteristics at 3 years in a well-defined group of ELBW children and to compare these language results with a sample of FBW children. Based on the results of the existing literature, poorer expressive and receptive language results were hypothesized in the children with ELBW.

\section{Subjects and Methods}

\section{Subjects}

The ELBW children of this study are part of a populationbased multi-center study $[5,6]$ on overall outcome to 3 years of age for extremely preterm infants born in Flanders during 19992000 (i.e. gestational age at birth $<27$ weeks). The ELBW group consisted of the first 15 healthy preterm children with a mean age of 3.3 years, corrected for prematurity. The mean birth weight was $793 \mathrm{~g}$ (range: $605-1,000 \mathrm{~g}$ ) and the mean gestational age was 25.1 weeks (range 23-26 weeks). We also included a group of 19 FBW children with a mean chronological age of 3.2 years. All FBW children were born beyond 39 weeks gestation and had a mean birth weight of $3,500 \mathrm{~g}$. The children were recruited through relatives of the ELBW children in order to minimize social and economic disparity and were all following normal education in a toddler school. All ELBW and FBW children were judged to be free of any major physical, sensorial and neurological impairment on clinical assessment at 3 years of age and had a mental developmental index $(\mathrm{MDI})>55$ on the Dutch version of the Bayley Scales of Infant Development, ed 2, with Dutch norms [7]. The ELBW group had significantly lower MDI scores (mean $=93.52, \mathrm{SD}=14.69)$ than the FBW group $($ mean $=106.00, S D=11.30), F(1,34)=7.07, p=0.002$. However, the mean MDI of both groups is situated in the normal range. The Four Factor Index of Social Status of Hollingshead [8] showed no significant difference regarding social status between the ELBW and the FBW group (Fisher's exact test, $\mathrm{p}=0.517$ ). Table 1 summarizes data of the ELBW group and the FBW group.

\section{Methods}

Language was tested using the Dutch version of the Reynell Developmental Language Scales [9]. This language test assesses multiple aspects of comprehension and production. The receptive vocabulary knowledge was assessed with understanding of a variety of named objects, verbs, adjectives, spatial prepositions, action-object semantic relations, comprehension of 'wh'-questions and comprehension of passive sentences. The Reynell Developmental Language Scales comprises three subtests for expressive language: vocabulary (naming items and pictures, defining concrete and abstract words), semantics (telling stories based on three pictures, and scores the ability to express semantic relations between the subjects, actions and location of the situation depicted) and an assessment of morphosyntactic abilities (production of different word classes, singular and plural forms, use of different verbs, etc.) from the spontaneous speech. Testing took place in a sound-protected room and was videotaped (Sony CCD-V900 E). The child was seated at a table in front of the speech pathologist. One or both parents were invited to join the testing session but were directed not to participate or encourage the child. The language test was completed in one 45 -min session. The BSID-II-Nl, mental scale, was completed in a previous session.

\section{Statistical Analysis}

The SPSS software (SPSS for Windows, version 10 advanced statistics, release 5; SPSS, Inc., Chicago, Ill., USA) was used. For the comparison of the expressive and receptive language results between the ELBW group and the FBW group, a univariate analysis of variance was used.

\section{Results}

The results of the expressive and receptive language characteristics in the ELBW group and the FBW group are presented in table 2 .

As presented in table 2, there was a significant difference between the ELBW group and the FBW group regarding the receptive and all the expressive language 
Table 2. Mean receptive and expressive language results (standardized values), standard errors and standard deviations

\begin{tabular}{|c|c|c|c|c|c|c|}
\hline \multirow[t]{2}{*}{ Subtests } & \multicolumn{2}{|c|}{ ELBW $(\mathrm{n}=15)$} & \multicolumn{2}{|c|}{ FBW $(\mathrm{n}=19)$} & \multirow[t]{2}{*}{$\mathrm{F}(1,34)$} & \multirow[t]{2}{*}{$\mathrm{p}$} \\
\hline & mean $\pm \mathrm{SE}$ & SD & mean $\pm \mathrm{SE}$ & SD & & \\
\hline Receptive language & $8.8 \pm 0.7$ & 2.65 & $10.6 \pm 0.6$ & 2.5 & $4.35^{*}$ & $0.045^{*}$ \\
\hline Expressive language & $8.7 \pm 1.0$ & 3.9 & $11.9 \pm 0.7$ & 2.9 & $7.70^{* *}$ & $0.009^{*}$ \\
\hline Vocabulary & $9.6 \pm 0.9$ & 3.6 & $12.0 \pm 0.7$ & 3.0 & $4.39^{*}$ & $0.044^{*}$ \\
\hline Semantics & $9.0 \pm 0.8$ & 3.1 & $11.7 \pm 0.6$ & 2.5 & $8.11^{* *}$ & $0.008^{*}$ \\
\hline Morphosyntaxis & $9.1 \pm 0.85$ & 3.3 & $11.4 \pm 0.7$ & 3.0 & $4.41^{*}$ & $0.044^{*}$ \\
\hline Total score & $8.5 \pm 0.9$ & 3.6 & $11.4 \pm 0.6$ & 2.7 & $7.24^{*}$ & $0.011^{*}$ \\
\hline
\end{tabular}

Effect sizes $\left({ }^{*} \mathrm{p}<0.05,{ }^{* *} \mathrm{p}<0.01\right.$, significant difference) for the ELBW group and the FBW group. $\mathrm{p}$ is the level of significance for the comparison of the expressive and receptive language results between the ELBW group and the FBW group. characteristics. In the ELBW group, 67\% (10/15) had normal language skills, 20\% (3/15) had a language problem (total language score $\leq$ percentile 15 ; raw value: 55 ; standardized value: 7$)$ and $13 \%(2 / 15)$ had a language disorder (total language score <percentile 3; raw value: 33; standardized value: 3$)$. In the FBW group, 95\% (18/19) had normal language skills and 3\% (1/19) had a language disorder.

An in-depth analysis of the receptive language skills showed that most of the ELBW children showed understanding of a variety of named objects and verbs. Most ELBW children responded correctly to instructions involving a simple action-object semantic relation. Sixtyone percent of the ELBW had difficulties understanding certain 'wh'-questions and 50\% of the ELBW children had problems with the comprehension of passive sentences like 'the dog is bitten by the rabbit'. Most of the ELBW children $(60 \%)$ also had difficulties with inferencing skills (e.g. 'John pushes the baby. Who is naughty?'). Seventy-five percent had difficulties understanding a number of spatial prepositions (such as under, in, on, ...) and some terms related to the size of objects (such as 'smallest, 'longest').

Regarding the expressive vocabulary, most ELBW children had the ability to recognize and produce the names of items. Forty-five percent of the children had difficulties recognizing pictures and naming items (verbs, adjectives, items, colors) and 54\% had difficulties defining concrete and abstract words ('can you tell me about noise, swimming, sleeping, hungry, a book, a dress). Significant differences between the ELBW and FBW were also seen for the subtest semantics. This subtest requires those being tested to tell stories based on three pictures ('setting the table', bedtime story telling', 'to horse about at the playground') and scores the ability to express semantic relations between the subjects, objects, actions, and location of the situation depicted and the ability to describe further details of the picture. Most of the ELBW children had difficulties expressing semantic relations of two elements (prepare dinner, reading books) and indicating some details. Most children were not able to capture the general theme of the situation depicted. The ELBW children just named objects and actions without further specifications.

A significant difference was also measured for the morphosyntactic abilities subtest. The most frequently produced words were substantives, verbs and personal pronouns. Of the substantives, most examples occurred in the singular form. Irregular plural forms did not occur. Verbs only occurred in the infinitive form. No examples were found of third-person singular, past participle or future tense. The average number of words per sentence, as calculated from the five longest sentences recorded, was 4.9. In controls, the average number of words per sentence was 6.5. Compound sentences, either by coordination of by subordination, were totally absent. In controls, compound sentences were present in $89 \%$ (17/19) of the children.

The results show that there was a strong and significant correlation between MDI and the receptive language and productive language scores in the ELBW group $(\mathrm{r}=$ $0.62, \mathrm{p}<0.01$ and $\mathrm{r}=0.57, \mathrm{p}<0.01$ ) as well as in the FBW group $(\mathrm{r}=0.44, \mathrm{p}<0.05$ and $\mathrm{r}=0.42, \mathrm{p}<0.05)$. 


\section{Discussion}

The main purpose of this study was to assess and analyze the language characteristics in 3-year-old ELBW children and to compare these language results with a sample of FBW children. Sixty-seven percent of the children with ELBW had normal language skills, while 33\% of the ELBW children showed a language problem or disorder. The expressive and receptive language results present evidence that in comparison to FBW controls, 3-yearold children whose mean birth weight was $793 \mathrm{~g}$ and mean gestational age was 25 weeks do present statistically significant poorer expressive and receptive language results. The findings of this study are consistent with the results of the investigation of Grunau et al. [2] who reported significant differences on language measures between ELBW and FBW children.

Although the mean MDI of both groups was in the normal range, we recognize that the mean MDI of the ELBW group was lower. The analyses showed a strong relation between the MDI and language functioning in the ELBW as well as in the FBW group. However, the MDI of the BSID-II does reflect a more general developmental index and not a pure cognitive score, as language items are incorporated in the score. Therefore, we can state that the mean language differences between ELBW and FBW children can partly be explained by a difference in general mental functioning, but are not simply due to a mental disability, physical or neurological differences. Social class differences cannot explain these significant differences either, given that the Four Factor Index of Social Status revealed no significant factor regarding social status between the ELBW and FBW children. Given that the age of the ELBW children was corrected for prematurity, the outcome would have been even worse in the preterm children if we had not corrected their age.

The authors are aware that there are a lot of intrinsic problems when sample sizes are small, as it is the case here. Variability in this population is large and the number of possibly influencing factors is huge. It should be noted that multiple variables, both known and unknown, can affect children's speech performance. The absence of mental disabilities, neurological disorders and sensorial impairments, the birth weight and the gestational age are known variables in this study. But variables such as increased length of hospital stay, periods of ventilation, parent-child interaction, other neonatal complications, children's motivation and other family, school and community factors are unknown and are all factors which can influence outcome [9], such as speech production.

According to the in depth analysis of the language characteristics, the logopedic approach of 3-year-old children born with ELBW must be focused on receptive (comprehension of 'wh'-questions, passive sentences, inferencing skills and spatial prepositions) and expressive (defining words, expressing semantic relations) morphosyntactic abilities and linguistic conceptualization. Both the otorhinolaryngologist and speech-language pathologist must be aware of these communication disorders that appear unrelated to neurological or sensorial impairments, but can be partly explained by a decreased general mental functioning. It should be pointed out that the small number of patients included in this study does not allow definite conclusions. Detailed analysis of a greater number of subjects may help further specify the longterm language outcomes after ELBW.

\section{References}

1 Aram DM, Hack M, Hawkins S, Weissman BM, Borawski-Clark E: Very-low-birthweight children and speech and language development. J Speech Hear Res 1991;34:11691179.

2 Grunau RVE, Kearny SM, Whitfield F: Language development at 3 years in pre-term children of birthweight below $1000 \mathrm{~g}$. Br J Disord Commun 1990;25:173-182.

-3 Le Normand MT, Vaivre-Douret L, Delfosse MJ : Language and motor development in pre-term children: some questions. Child Care Health Dev 1995;21:119-133.
-4 Luoma L, Herrgard MD, Martikainen A, Ahonen T: Speech and language development of children born at $\leq 32$ weeks' gestation: a 5-years prospective follow-up study. Dev Med Child Neurol 1998;40:380-387.

5 De Groote I, Vanhaesebrouck P, Bruneel E, Dom L, Durein I, Hasaerts D, Laroche S, Oostra A, Ortibus E, Roeyers H, van Mol C: Overall outcome at 3 years of age in a population-based cohort of extremely preterm infants. Obstet Gynecol 2007;110:855-864.

-6 Vanhaesebrouck P, Allegaert K, Bottu J, Debauche C, Devlieger H, Docx M, et al: The EPIBEL Study: outcomes to discharge from hospital for extremely preterm infants in Belgium. Pediatrics 2004;114:663-675.
7 van der Meulen BF, Ruiter SA, Spelberg LHC, Smrkovský M: Bayley Scales of Infant Development (BSID). II. Nederlandse versie. Lisse, Swets Test Publishers, 2002.

8 Hollingshead AB: Four factor index of social status. Unpublished manuscript, Yale University, 1975.

9 Scharlaekens A, Zink I, van Ommeslaeghe K: Reynell Taalontwikkelingsschalen. Lisse, Swets \& Zeitlinger, 2003. 